(RESEARCH ARTICLE)

\title{
Effect of gluteus medius strengthening on pain perception, functional disability and quality of life in patients with non-specific chronic low back pain.
}

\author{
Famude Samuel Olawale ${ }^{1,}{ }^{*}$, Odebiyi Olufem Daniel ${ }^{2}$, Aiyegbusi Ayoola Ibifubara ${ }^{2}$, Komolafe Olumide \\ Adeoye ${ }^{1}$ and Nwosu Ifeoma Blessing ${ }^{3}$ \\ ${ }^{1}$ Department of Physiotherapy, Lagos State University Teaching Hospital (LASUTH), Ikeja Lagos Nigeria. \\ 2 Department of Physiotherapy, College Of Medicine, University Of Lagos, Idi-Araba Lagos Nigeria. \\ ${ }^{3}$ Department of Physiotherapy Nnamdi Azikiwe University, Awka, Anambra State Nigeria.
}

Publication history: Received on 17 February 2020; revised on 04 March 2020; accepted on 06 March 2020

Article DOI: https://doi.org/10.30574/wjarr.2020.5.3.0047

\begin{abstract}
Low back pain (LBP) poses a serious challenge worldwide to the health care system. Therapeutic exercises are considered one of the major interventions for decreasing pain and increasing self-efficacy. Gluteus Medius muscle has been found to be weak and tender in patients with Non-specific Chronic Low Back Pain (LBP). This study therefore aimed to establish the effect of Gluteus Medius strengthening on pain, functional disability, quality of life and physical activity of individuals with NSCLBP. Fifty (50) individuals with NSCLBP were recruited from two hospitals in Lagos State Nigeria. Participants were randomly assigned into two groups: Participants in group one received stabilization exercises, while participants in group two received gluteus Medius strengthening exercises in addition to stabilization exercises. Measurement of pain, functional disability, quality of life and physical activity were measured using the Numerical rating scale, Oswestry disability index, SF-36 questionnaire and International Physical Activity Questionnaire respectively at baseline, $4^{\text {th }}$ week and $8^{\text {th }}$ week post intervention. Independent t-test was used to compare the variables between the groups and repeated measure ANOVA was used to compare variables within the groups at 95\% confident interval. Findings from this study revealed improved clinical outcomes in all variables in the two groups post intervention $(\mathrm{p}<0.05)$ for pain, functional disability and physical activity respectively, group one $(0.005,0.001,0.000)$ group two $(0.001,0.004,0.000)$. However, there was statistically significant difference between the groups. Participants in group two had better clinical outcome at the end of the 4th week of treatment. There was decreased pain intensity $(\mathrm{p}<0.001)$, increased functional ability $(\mathrm{p}<0.001)$, increased physical activity $(\mathrm{p}<0.02)$ and improved quality of life $(0.00,0.01,0.00,0.01)$ respectively. All participants had improved clinical outcomes at the end of 8th week post intervention, however those in group two had better improvement by the end of 4 th week of treatment. Hence, combined stabilization exercise and Gluteus Medius strengthening may be preferred as it brought about improvement at reduced treatment sessions. It is recommended that Physical Therapists should always assess the strength of the gluteus medius muscle in patients with NSCLBP, and strengthen the muscle when weakness is noticed.
\end{abstract}

Keywords: Non-specific chronic low back pain; Gluteus Medius strengthening; Functional disability; Quality of life; Physical activity.

\section{Introduction}

Low back pain (LBP) is the pain that occurs within the area with boundaries between the lowest ribs and crease of the buttocks (Venkata and Sreeka, 2015) [1] and it poses a serious challenge worldwide to the health care system (Naidoo et al, 2012) [2]. Therapeutic exercises are considered one of the major interventions for decreasing pain and increasing self-efficacy (Airaksinen et al, 2006) [3]. Cooper et al (2015) [4], reported that the gluteus medius muscle has been found to be weak and tender in patients with non-specific chronic low back pain. This study therefore aimed

${ }^{*}$ Corresponding author: Famude Samuel Olawale

Copyright (C) 2020 Author(s) retain the copyright of this article. This article is published under the terms of the Creative Commons Attribution Liscense 4.0. 
Famude et al. / World Journal of Advanced Research and Reviews, 2020, 05(03), 018-024

to establish the effect of gluteus medius strengthening on pain, functional disability, quality of life and physical activity of individuals with Non-Specific Chronic Low Back Pain (NSCLBP).

\section{Material and methods}

Fifty (50) Participants with Non-specific chronic low back pain from the Lagos State University Teaching Hospital (LASUTH) Ikeja Nigeria, and Lagos University Teaching Hospital (LUTH) Idi-Araba, Nigeria participated in this study.

Inclusion Criteria were Patients with recurrent history of LBP of not less than 3 months, patients with history of nonspecific chronic low back pain with or without pain radiating to one or both lower limbs.

Exclusion Criteria were patients with previous spinal surgeries, history of trauma to the back, spinal deformity, history of unexplained weight loss, specific low back pain e.g. LBP referred from cancer.

Participants were assigned into two different groups (study and control) using a computer generated random number sequence and obtained before meeting the participants thereby enabling the participants to fall into any of the two groups according to the order of their presentation.

\subsection{Study group (26)}

Participants in this group performed gluteus medius strengthening exercises combined with stabilization exercises in addition to infrared radiation and back care instructions.

\subsection{Control group (24)}

Participants in this group performed core stabilization exercises in addition to Infrared radiation and back care instructions.

Components of stabilization exercise used in this study included Abdominal bracing, Bracing with heel slides, Bracing with bridging, Bracing with leg lift, Quadruped arms lift with bracing, Quadruped leg lift with bracing (Jean-Alexandre et al, 2016) [5]. The training session was scheduled for 2 times in a week for 8 weeks and were performed for 10 seconds and 10repititions. The values of pain using the Numerical rating scale (NRS), Quality of life using the SF-36 questionnaire, Functional disability using the Oswestry disability index (ODI) and Physical activity using the international physical activity questionnaire (IPAQ) were measured at baseline, $4^{\text {th }}$ week and $8^{\text {th }}$ week respectively.

Components of gluteus medius strengthening used in the study included; Clam shell exercises, Hip abduction side lying exercises, Hip abduction side lying with weight exercises (David et al, 2013) [6].

Ethical approval was sought and obtained from the Health Research and Ethics Committee of the Lagos State University Teaching Hospital (LASUTH) Ikeja (Appendix I) approval number: LREC/06/10/694, and Lagos University Teaching Hospital (LUTH) Idi-Araba (Appendix II) with approval number: ADM/DCST/HREC/APP/996. Participants' consent was also sought and obtained before the commencement of the study (Appendix III), confidentiality of all information obtained was assured.

\section{Results}

Fifty (50) participants with non-specific chronic low back pain completed the study, twenty four (24) participants were in group 1 (control group) and twenty six (26) participants were in group 2 (study group).

The mean age of participants in group 1 and 2 were $54.21 \pm 5.66$ and $52.77 \pm 4.68$ years respectively. Twenty two (44\%) of the participants were male and twenty six (56\%) were female. The mean Body Mass Index (BMI) of the participants in group 1 and 2 were $26.00 \pm 2.08 \mathrm{~kg} / \mathrm{m}^{2}$ and $25.42 \pm 1.67 \mathrm{~kg} / \mathrm{m}^{2}$ respectively. The two groups did not differ significantly in age and body mass index @ $\mathrm{p}<0.05$ (Table 1). Comparison of the baseline mean values using independent sample test revealed that there was no significant difference in baseline characteristics in the groups with respect to pain intensity, functional disability, physical activities and quality of life scores ( $p>0.05$ in all cases) (Table 2). 
Table 1 Physical characteristics of the participants

\begin{tabular}{lllll}
\hline & $\begin{array}{l}\text { All } \\
\text { participants } \\
\mathbf{X} \pm \text { SD } \\
\mathbf{N = 5 0}\end{array}$ & $\begin{array}{l}\text { GROUP 1 } \\
\mathbf{X} \pm \mathbf{S D} \\
\mathbf{N = 2 4}\end{array}$ & $\begin{array}{l}\text { GROUP 2 } \\
\mathbf{X} \pm \text { SD } \\
\mathbf{N = 2 6}\end{array}$ & P-value \\
& $53.49 \pm 5.17$ & $54.21 \pm 5.67$ & $52.77 \pm 4.68$ & 0.21 \\
\hline AGE (Yrs) & $1.73 \pm 2.18$ & $1.71 \pm 2.16$ & $1.75 \pm 2.20$ & 0.33 \\
HEIGHT (m) & $76.98 \pm 8.89$ & $76.03 \pm 9.70$ & $77.85 \pm 8.08$ & 0.41 \\
WEIGHT (kg) & $25.72 \pm 1.87$ & $26.00 \pm 2.08$ & $25.42 \pm 1.67$ & 0.48 \\
BMI (Kg/m2) & KEY: X \pm SD Mean \pm Standard Deviation; BMI = Body Mass Index & \\
\hline
\end{tabular}

Group 1= Core Stabilization exercise only.

Group 2= Core Stabilization exercise + Gluteus medius strengthening exercise.

Table 2 Baseline Characteristics of participants

\begin{tabular}{llllll}
\hline & $\begin{array}{l}\text { All participants } \\
\mathbf{X} \pm \text { SD N=50 }\end{array}$ & $\begin{array}{l}\text { GROUP 1 } \\
\mathbf{X} \pm \mathbf{S D ~ N = 2 4}\end{array}$ & $\begin{array}{l}\text { GROUP 2 } \\
\mathbf{X} \pm \mathbf{S D N = 2 6}\end{array}$ & t-value & p-value \\
\hline PAIN & $9.10 \pm 0.80$ & $8.92 \pm 0.93$ & $9.27 \pm 0.67$ & 1.53 & 0.31 \\
FD & $32.28 \pm 4.73$ & $31.29 \pm 5.01$ & $32.63 \pm 4.45$ & 1.00 & 0.54 \\
PA & $4.43 \pm 1.30$ & $4.09 \pm 0.74$ & $4.57 \pm 1.86$ & 1.22 & 0.19 \\
PF & $4.42 \pm 5.07$ & $4.58 \pm 5.09$ & $4.25 \pm 5.04$ & -0.25 & 0.64 \\
E & $17.05 \pm 3.37$ & $16.93 \pm 3.41$ & $17.17 \pm 3.33$ & 0.25 & 0.64 \\
SE/W & $42.91 \pm 3.22$ & $42.91 \pm 2.17$ & $42.91 \pm 4.27$ & 0.03 & 0.32 \\
GH & $44.82 \pm 6.84$ & $43.21 \pm 5.65$ & $46.42 \pm 8.02$ & 1.65 & 0.76
\end{tabular}

KEY: $\mathrm{X} \pm \mathrm{SD}=$ Mean \pm Standard Deviation; FD = Functional Disability; PA = Physical Activity; PF = Physical Function; E = Energy; S/EW = Social and Emotional well-being; $\mathrm{GH}=$ General Health

\subsection{Comparison of mean changes of outcome variables of participants within the two groups at baseline and $4^{\text {th }}$ week, baseline and $8^{\text {th }}$ week post intervention}

A detailed comparison of mean changes within group 1 and group 2 was conducted to compare the differences of mean changes in outcome of pain, functional disability, physical activity and quality of life at baseline, end of $4^{\text {th }}$ week and $8^{\text {th }}$ week post intervention. The clinical outcome variables after 16 sessions (8weeks) are presented in Table 3 and 4 respectively. Table 3 reveals that there was statistically significant difference in pain, functional disability and physical activity for group 1 and group 2 .

Table 4 shows a detailed comparison of mean changes within Group 1 and Group 2 for the analysis of physical functioning, energy, social/emotional well-being, and general health domain of quality of life questionnaire at baseline, end of $4^{\text {th }}$ week and $8^{\text {th }}$ week post intervention respectively. The table shows that there were statistically significant changes in physical function, energy, social/emotional well-being, and general health domain of quality of life questionnaire in group 1 and group 2. 
Table 3 Comparison of mean changes of outcome variables of participants within the two groups at baseline, end of $4^{\text {th }}$ week and $8^{\text {th }}$ week post intervention.

\begin{tabular}{lllllll}
\hline & & $\begin{array}{l}\text { Baseline } \\
\mathbf{X} \pm \text { SD }\end{array}$ & $\begin{array}{l}4^{\text {th }} \text { week } \\
\mathbf{X} \pm \mathbf{S D}\end{array}$ & $\begin{array}{l}\mathbf{8}^{\text {th }} \text { week } \\
\mathbf{X} \pm \text { SD }\end{array}$ & F-value & p-value \\
\hline Group1 & Pain & $8.92 \pm 0.93$ & $4.75 \pm 0.44$ & $0.63 \pm 0.50$ & 19.85 & $0.005^{*}$ \\
& FD & $31.29 \pm 5.01$ & $52.20 \pm 1.83$ & $93.33 \pm 2.28$ & -19.20 & $0.001^{*}$ \\
& PA & $4.09 \pm 0.74$ & $8.29 \pm 0.78$ & $16.75 \pm 1.66$ & -22.59 & $0.000^{*}$ \\
Group 2 & Pain & $9.27 \pm 0.67$ & $2.15 \pm 0.37$ & $0.65 \pm 0.37$ & 47.64 & $0.001^{*}$ \\
& FD & $32.69 \pm 4.45$ & $81.61 \pm 2.63$ & $92.22 \pm 7.80$ & -46.64 & $0.004^{*}$ \\
& PA & $4.57 \pm 1.86$ & $13.34 \pm 1.05$ & $16.82 \pm 1.64$ & -20.92 & $0.000^{*}$ \\
\hline
\end{tabular}

$\mathrm{KEY}: \mathrm{X} \pm \mathrm{SD}=$ Mean \pm Standard Deviation; SD = Standard Deviation; FD = Functional Disability; PA = Physical Activity

Table 4 Comparison of mean changes in quality of life variables of participants within the two groups at baseline, end of $4^{\text {th }}$ week and $8^{\text {th }}$ week post intervention.

\begin{tabular}{lllcccc}
\hline & & $\begin{array}{l}\text { Baseline } \\
\mathbf{X} \pm \mathbf{S D}\end{array}$ & $\begin{array}{l}\mathbf{4}^{\text {th }} \text { week } \\
\mathbf{X} \pm \mathbf{S D}\end{array}$ & $\begin{array}{l}\mathbf{8}^{\text {th }} \text { week } \\
\mathbf{X} \pm \mathbf{S D}\end{array}$ & \multicolumn{1}{c}{ F- value } & p-value \\
\hline Group 1 & $\mathrm{PF}$ & $4.58 \pm 5.09$ & $50.0 \pm 0.00$ & $97.50 \pm 2.55$ & -55.61 & $0.000^{*}$ \\
& $\mathrm{E}$ & $16.93 \pm 3.41$ & $63.25 \pm 2.88$ & $82.82 \pm 4.77$ & -63.27 & $0.015^{*}$ \\
& $\mathrm{~S} / \mathrm{EW}$ & $42.91 \pm 2.17$ & $65.2 \pm 4.03$ & $93.49 \pm 2.03$ & -33.18 & $0.018^{*}$ \\
& $\mathrm{GH}$ & $43.21 \pm 5.65$ & $54.04 \pm 3.34$ & $90.77 \pm 3.92$ & -12.04 & $0.023^{*}$ \\
Group 2 & $\mathrm{PF}$ & $4.23 \pm 5.04$ & $73.65 \pm 3.89$ & $97.23 \pm 2.77$ & -55.62 & $0.000^{*}$ \\
& $\mathrm{E}$ & $17.17 \pm 3.38$ & $76.14 \pm 3.38$ & $83.09 \pm 3.41$ & -62.99 & $0.001^{*}$ \\
& $\mathrm{~S} / \mathrm{EW}$ & $42.92 \pm 4.27$ & $79.15 \pm 1.99$ & $94.35 \pm 2.30$ & -39.18 & $0.007^{*}$ \\
& $\mathrm{GH}$ & $46.4 \pm 8.02$ & $74.62 \pm 4.67$ & $90.63 \pm 3.99$ & -15.49 & $0.010^{*}$ \\
\hline
\end{tabular}

KEY: $\mathrm{X} \pm \mathrm{SD}=$ Mean \pm Standard Deviation; $\mathrm{PF}=$ Physical Function; $\mathrm{E}=$ Energy; $\mathrm{S} / \mathrm{EW}=$ Social and Emotional well-being; GH = General Health

\subsection{Comparison of clinical outcome parameters between the two groups}

Comparison of means between the two groups shows that there were significant difference in pain, functional disability and physical activity at the end of the $4^{\text {th }}$ week and no significant difference at $8^{\text {th }}$ week (Table 5), and there were significant difference in physical function, energy, social/emotional well-being and general health domains of the SF-36 questionnaire at the end of the $4^{\text {th }}$ week and no significant difference at $8^{\text {th }}$ week (Table 6 ). 
Table 5 Comparison of mean changes in clinical outcome parameters of participants between the two groups at baseline, end of $4^{\text {th }}$ and $8^{\text {th }}$ week post intervention.

\begin{tabular}{llllll}
\hline \multirow{6}{*}{ Baseline } & & $\begin{array}{l}\text { Group 1 } \\
\mathbf{X} \pm \text { SD }\end{array}$ & $\begin{array}{l}\text { Group 2 } \\
\mathbf{X} \pm \text { SD }\end{array}$ & U-value & p-Value \\
& Pain & $8.92 \pm 0.93$ & $9.27 \pm 0.67$ & 1.53 & 0.31 \\
& FD & $31.29 \pm 5.01$ & $32.63 \pm 4.45$ & 1.00 & 0.54 \\
& PA & $4.43 \pm 1.30$ & $4.57 \pm 1.86$ & 1.23 & 0.19 \\
\multirow{2}{*}{ th Week } & Pain & $4.75 \pm 0.44$ & $2.15 \pm 0.37$ & -22.63 & $0.00^{*}$ \\
& FD & $52.20 \pm 1.83$ & $81.61 \pm 2.63$ & 45.55 & $0.00^{*}$ \\
& PA & $8.29 \pm 0.78$ & $13.34 \pm 1.05$ & 19.25 & $0.02^{*}$ \\
& Pain & $0.63 \pm 0.50$ & $0.65 \pm 0.37$ & -3.84 & 0.33 \\
& FD & $93.33 \pm 2.28$ & $92.22 \pm 7.80$ & -0.86 & 0.51 \\
& PA & $16.75 \pm 1.66$ & $16.82 \pm 1.64$ & 0.15 & 0.18 \\
\hline
\end{tabular}

$\mathrm{KEY}: \mathrm{X} \pm \mathrm{SD}=$ Mean \pm Standard Deviation; FD = Functional Disability; PA = Physical Activity

Table 6 Comparison of mean changes in quality of life variables between the two groups at baseline, end of $4^{\text {th }}$ and $8^{\text {th }}$ week post intervention.

\begin{tabular}{llllll}
\hline & & Group1 & Group2 & U-value & p-value \\
\hline Baseline & PF & $4.58 \pm 5.09$ & $4.25 \pm 5.04$ & -2.46 & 0.64 \\
& E & $16.93 \pm 3.41$ & $17.17 \pm 3.33$ & 2.46 & 0.64 \\
4th Week & S/EW & $42.91 \pm 2.17$ & $42.91 \pm 4.27$ & 0.03 & 0.32 \\
& GH & $43.21 \pm 5.65$ & $46.42 \pm 8.02$ & 1.65 & 0.76 \\
& PF & $50.00 \pm 0.00$ & $73.65 \pm 3.89$ & 31.02 & $0.00^{*}$ \\
& E & $63.25 \pm 2.88$ & $76.14 \pm 3.38$ & 14.56 & $0.01^{*}$ \\
& S/EW & $65.21 \pm 4.03$ & $79.15 \pm 1.99$ & 15.69 & $0.00^{*}$ \\
& GH & $54.04 \pm 3.34$ & $74.62 \pm 4.67$ & 18.00 & $0.01^{*}$ \\
& PF & $97.50 \pm 2.55$ & $97.23 \pm 2.77$ & -0.94 & 0.63 \\
& E & $82.82 \pm 4.77$ & $83.09 \pm 3.41$ & 0.24 & 0.60 \\
& S/EW & $93.49 \pm 2.03$ & $94.35 \pm 2.30$ & -1.40 & 0.30 \\
& GH & $90.77 \pm 2.77$ & $90.63 \pm 3.99$ & 0.13 & 0.77 \\
\hline
\end{tabular}

KEY: $\mathrm{X} \pm \mathrm{SD}=$ Mean \pm Standard Deviation; PF = Physical Function; $\mathrm{E}=$ Energy; $\mathrm{S} / \mathrm{EW}=$ Social and Emotional well-being; GH = General Health

\section{Discussion}

Participants in the two groups were similar in age and physical characteristics and this suggests that the two groups were homogenous and therefore comparable.

In this randomized controlled study, marked improvement in clinical outcomes (Pain intensity, Functional disability, Physical activity and Quality of life) were observed within the two groups i.e. core stabilization exercise group and core stabilization combined with gluteus medius strengthening exercise group after 4weeks and 8weeks of intervention respectively. 
This findings support the result of the study by Akodu et al (2015) [7], who reported that stabilization exercise is effective in the management of NSCLBP. The study is also in agreement with the study by Ui-cheol et al (2015) [8], who assessed the effect of stabilization exercises combined with hip strengthening exercise on patients with NSCLBP and found the exercises to be effective in the management of NSCLBP.

The findings that there was significant difference in clinical outcome parameters within the two groups at the end of 8weeks treatment sessions support the use of exercise therapy in the management of patients with NSCLBP; However this study shows that there was marked improvement in Pain, Functional disability, physical activity and Quality of life of participants who had core stabilization exercise combined with gluteus medius strengthening at the end of 4 weeks of treatment period. This findings support the result of a study conducted by Kendall, (2013) [9] who reported a 48\% reduction in low back pain after 3weeks of hip strengthening exercises for patients with NSCLBP in a study exploring the relationship between hip strengthening, lumbopelvic mechanics and pain in Non-Specific Chronic Low Back Pain patients.

Findings from this study reports that gluteus medius strengthening exercise combined with stabilization exercise were more effective at the end of 4weeks resulting in a decrease in pain perception, increased physical activity and increase in functional abilities of patients with NSCLBP. This improvement could be attributed to an increased lumbar segmental stability from the stabilization exercise and increased stability of the pelvis and hip joint as a result of the gluteus medius strengthening exercise (Kendall, 2013) [9].

This study also revealed that there was improvement in physical function, energy, social/emotional well-being and general health i.e. improved quality of life of participants in this study. However, there was a more significant effect on outcome variables of participants who had gluteus medius strengthening combined with stabilization exercise at the end of the $4^{\text {th }}$ week of treatment period, this findings were corroborated by Ui-cheol et al [8], 2015 who reported that lumbar stabilization exercise combined with hip strengthening exercise resulted in a decrease in pain, low back pain disability index, increased lumbar muscle strength and balance with maintenance of smooth daily living.

To sum up the results, both stabilization exercise only and gluteus medius strengthening exercise combined with stabilization exercise were effective for improving pain, functional disability, and quality of life in patients with NSCLBP.

Comparison of the changes between the two groups revealed that there was a more significant effect on Pain, Functional disability, physical activity and Quality of life among the participants with NSCLBP who had stabilization exercise combined with gluteus medius strengthening exercise at the end of the $4^{\text {th }}$ week of treatment session, and it is considered that core stabilization exercises strengthened the deep core muscles of the low back thereby increasing lumbar segmental stability, and the gluteus medius strengthening exercise increased the stability of the pelvis and hip joint.

Comparison of the changes between the two groups revealed that there was no significant effect on Pain, Functional disability, physical activity and Quality of life among the participants with NSCLBP at the end of $8^{\text {th }}$ week of intervention for both groups this revealed that both groups had good improvement in their outcome variables on a long term basis.

\section{Conclusion}

Findings in this study revealed that stabilization exercises combined with gluteus medius strengthening exercise has been found to be more beneficial in bringing about quick recovery in pain, functional disability and quality of life in patients with Non-specific chronic low back pain.

\section{Compliance with ethical standards}

\section{Acknowledgments}

I wish to express my profound gratitude to God almighty for the successful completion of this study, my sincere appreciation goes to Dr Femi Odebiyi and Dr Ayoola Ayegbusi and the entire staff of the College of Medicine University of Lagos Idi-Araba for their immense contribution to this study. Sincere appreciation also goes to Mr Komolafe Olumide for being the inspiration behind the topic and his support all through the course of the study, I also appreciate the immense contribution of Mrs. Nwosu Ifeoma not also forgetting Mrs. Eze Uju for her contribution too. I 
also thank my wife (Abisola) and children (Temitayo and Temitope) for their love, support and care throughout the course of this study. God bless you all.

\section{Disclosure of conflict of interest}

There are no conflict of interest from any of the authors involved.

\section{Statement of informed consent}

Informed consent was obtained from all individual participants included in the study.

\section{References}

[1] Venkata NP and Sreekar KR. (2015). Core stabilization training and conventional exercises in patients with mechanical low back pain. International Journal of Physiotherapy, 2(1), 352-360.

[2] Naidoo V, Mudzi W, Ntsie V and Becker PJ. (2012). Physiotherapy Modalities used in Management of Chronic Low Back Pain. South African Journal of Physiotherapy, 68, 1.

[3] Airaksinen O, Brox H, Cedraschi C, Hildebrandt J, Klaber-Moffelt J and Kovacs F. (2006). European guidelines for management of chronic non-specific low back pain. European spine journal, 15, 192-300.

[4] Cooper NA, Scavo KM, Strickland KJ, Tipayamonqkol N, Nicholson JD, Bewyer DC and Sluka KA. (2015). Prevalence of gluteus medius weakness in people with chronic low back pain compared to healthy controls. European Spine Journal, 24(2), 60-67.

[5] Jean-Alexandre B, Richard P, Sharon MH, Jean-Pierre D and Christian L. (2016). The effects of an 8-week stabilization exercise program on lumbar movement sense in patients with low back pain. Biomed central Musculoskeletal Disorders, 17, 23.

[6] David M, George J and Christopher M. (2013). Which exercises target the gluteal muscles while minimizing activation of the tensor facialata? Electromyographic assessment using fine-wire electrodes. Journal of Orthopaedic \& Sports Physical Therapy, 43(2), 54-64.

[7] Akodu AK, Akinbo SR and Odebiyi DO. (2015). Effects of stabilization exercise on pain and disability in patients with chronic low back pain. Indian Journal of Physical Therapy and occupational therapy, 9(2), 170-175.

[8] Ui-Cheol J, Jea-Heon S, Cheol-yong K, Gak H and Chan-Woo N. (2015). The effect of gluteus muscle strengthening and lumbar stabilization exercise on lumbar muscle strength and balance in chronic low back pain patients. Journal of physical therapy and science, 27(12), 3813-3816.

[9] Kendall KD. (2013). Lumbopelvic stability in non-specific low back pain: Exploring the relationship between hip strengthening, lumbopelvic mechanics and pain (PHD Thesis). University of Calgary Alberta.

\section{How to cite this article}

Famude SO, Odebiyi OD, Aiyegbusi AI, Komolafe OA and Nwosu IB. (2020). Effect of gluteus medius strengthening on pain perception, functional disability and quality of life in patients with non-specific chronic low back pain. World Journal of Advanced Research and Reviews, 5(3), 18-24. 